\title{
Article \\ Modulation of Gene Expression in a Sterile Atopic Dermatitis Model and Inhibition of Staphylococcus aureus Adhesion by Fucoidan
}

\author{
Ah Young Park ${ }^{1, *(\mathbb{D})}$, Maureen Bourtembourg ${ }^{2}$, Aline Chrétien ${ }^{2}$, Roland Hubaux ${ }^{2}\left(\mathbb{D}\right.$, Céline Lancelot ${ }^{2}$, \\ Michel Salmon ${ }^{2}$ and J. Helen Fitton ${ }^{1, *}$ \\ 1 Marinova Pty Ltd., 249 Kennedy Drive, Cambridge, TAS 7170, Australia \\ 2 StratiCELL, Crealys Science Park, Rue Jean Sonet 10, B-5032 Isnes, Belgium; \\ mbourtembourg@straticell.com (M.B.); achretien@straticell.com (A.C.); rhubaux@straticell.com (R.H.); \\ clancelot@straticell.com (C.L.); msalmon@straticell.com (M.S.) \\ * Correspondence: ahyoung.park@marinova.com.au (A.Y.P.); helen.fitton@marinova.com.au (J.H.F.)
}

\section{check for} updates

Citation: Park, A.Y.; Bourtembourg, M.; Chrétien, A.; Hubaux, R.;

Lancelot, C.; Salmon, M.; Fitton, J.H. Modulation of Gene Expression in a Sterile Atopic Dermatitis Model and Inhibition of Staphylococcus aureus Adhesion by Fucoidan.

Dermatopathology 2021, 8, 69-83.

https://doi.org/10.3390/

dermatopathology 8020012

Academic Editor: Gürkan Kaya

Received: 3 March 2021

Accepted: 18 March 2021

Published: 25 March 2021

Publisher's Note: MDPI stays neutral with regard to jurisdictional claims in published maps and institutional affiliations.

Copyright: (c) 2021 by the authors. Licensee MDPI, Basel, Switzerland. This article is an open access article distributed under the terms and conditions of the Creative Commons Attribution (CC BY) license (https:/ / creativecommons.org/licenses/by/ $4.0 /)$.

\begin{abstract}
Atopic dermatitis is a multifactorial pathology that includes perturbations of gene expression and increased adhesion of Staphylococcus aureus. Fucoidans are seaweed-derived sulfated fucose-rich polysaccharides that are known to be anti-inflammatory and may inhibit adhesion of pathogens. Fucoidan was assessed for effects on gene expression of an in vitro 3D model of atopic dermatitis. It was also assessed for inhibitory effects on the adhesion of bacteria onto 3D reconstructed skin. Fucoidan significantly altered gene expression in the atopic dermatitis model, and there was a trend to reduce periostin levels. Fucoidan significantly inhibited the adhesion of Staphylococcus aureus and Cutibacterium acnes but did not affect the adhesion of Staphylococcus epidermidis. Fucoidan may be a useful topical agent to assist in the management of atopic dermatitis.
\end{abstract}

Keywords: atopic dermatitis; Staphylococcus aureus; fucoidan; periostin; reconstructed human epidermis

\section{Introduction}

Atopic dermatitis (AD) is a multifactorial debilitating skin condition that is associated with the bacteria Staphylococcus aureus, and alterations in the expression of genes involved in barrier function, itch and inflammation. A combination of environmental exposure, epidermal barrier disruption and immune dysregulation are all part of this condition, which includes severe pruritus and eczematous changes. Bacterial involvement may not be an initiator of the condition, but a sequel to it. Treatment of atopic dermatitis may involve both topical and systemic steroids, methotrexate, biological immunomodulators and antibiotics. The disease burden of AD is considerable, affecting people of all ages and ethnicities [1], and there is an unmet need for effective, non-toxic treatments.

Fucoidans are brown seaweed-derived sulfated fucose-rich polysaccharides that are known to be anti-inflammatory [2,3] and may inhibit the adhesion of pathogens $[4,5]$. Fucoidan is classically known as a selectin and scavenger receptor blocking agent [6]. By blocking these cellular adhesion molecules, fucoidan can prevent the intrusion of neutrophils into tissue spaces, attenuating inflammatory responses. Pharmaceutical agents that target a specific pro-inflammatory pathway in AD have been greatly explored [7]. Fucoidan has significantly reduced the elevated level of $\mathrm{IgE}$ in human peripheral blood mononuclear cells of AD patients in vitro [8] and topical fucoidan has been shown to ameliorate AD in a mouse model $[9,10]$. Despite these beneficial effects of fucoidan in AD, it is not known how fucoidan affects human epidermal keratinocytes and its gene expression.

Reconstructed human epidermis (RHE) provides a great in vitro research platform, since it mimics layering, differentiation and barrier function of normal human in vivo epidermis [11]. Keratinocytes form the outermost layer of the skin and constitute $90 \%$ of epidermal skin 
cells. When pathogens are introduced onto the surface of skin, keratinocytes begin to produce pro-inflammatory mediators, leading to phenotype features of AD [12]. AD is characterized by an imbalance of the Th1/Th2 and during the acute phase of the disease, Th2-mediated cytokines such as interleukin-4, -13 and-25 are overly expressed [13]. Introduction to these interleukins to RHE induces histological and gene expressions changes typical to the AD patients [14].

In this research, we sought to understand how fucoidan might affect gene expression and periostin production in an in vitro 3D-RHE of keratinocyte model of atopic dermatitis using Th2-mediated cytokines. Periostin is significantly overexpressed in AD patients [15-18] and in our Th2 cytokine stimulated model [14,19]. We then explored how fucoidan could affect the adhesion of three types of human skin bacteria-the pathogenic Staphylococcus aureus, commensal Staphylococcus epidermidis and Cutibacterium acne.

\section{Methods and Materials}

\subsection{Materials}

Fucoidan extracts from Fucus versiculosus (FV) and Undaria pinnatifida (UP) were provided by Marinova Pty Ltd. (Cambridge, Australia). The proprietary aqueous extract was designed for topical application and specific properties are described in Table 1.

Table 1. Description of Fucus versiculosus (FV) and Undaria pinnatifida (UP).

\begin{tabular}{cccccc}
\hline $\begin{array}{c}\text { Fucoidan } \\
\text { Extract }\end{array}$ & $\begin{array}{c}\text { Neutral } \\
\text { Carbohydrates }\end{array}$ & Sulfate & $\begin{array}{c}\text { Cations } \\
\text { (approx.) }\end{array}$ & Fucoidan & Polyphenol \\
\hline FV & $43.7 \%$ & $10.1 \%$ & $3 \%$ & $58.6 \%$ & $33.7 \%$ \\
UP & $48.8 \%$ & $27.4 \%$ & $9 \%$ & $89.6 \%$ & $<2 \%$ \\
\hline
\end{tabular}

\subsection{Reconstructed Human Epidermis-RHE}

The study was carried out on epidermis in vitro, reconstituted with NHEKs keratinocytes isolated from foreskin of 3 Caucasian donors (RHE). The tissues were cultured at the air-liquid interface, during 14 days, in Epilife medium (Fisher Scientific, Merelbeke, Belgium, M-EPI-500-A) containing supplements and antibiotics (Gentamycin, Fisher Scientific, 15710-049). They were maintained in a humid atmosphere at $37^{\circ} \mathrm{C}$ with $5 \% \mathrm{CO}_{2}$.

\subsection{Induction of the Th2-Inflamed Model}

Three Th2-related cytokines (IL-4, IL-13 and IL-25) interleukins were applied on the culture medium of RHE at the concentrations of $50 \mathrm{ng} / \mathrm{mL}$ for IL-4 and IL-13, and $20 \mathrm{ng} / \mathrm{mL}$ for IL-25, during $48 \mathrm{~h}$ to induce alterations and gene expression modulations reminiscent to AD and a sensitive skin [14,20-22].

\subsection{Treatment of the Epidermis-Gene Expression}

FV and UP were diluted in PBS at $100 \mu \mathrm{g} / \mathrm{mL}$ and applied topically on RHE during the $48 \mathrm{~h}$ of stimulation. A mesh has been applied on the stratum corneum to allow the even distribution of testing compounds on the tissue surface. For control PBS had been applied topically on Th2-stimulated RHE, with addition of a mesh.

As a reference treatment GW3965 $(10 \mu \mathrm{M})$ was applied in the culture medium during the same $48 \mathrm{~h}$ in combination with the cytokines. GW3965 is an LXR agonist that modulates the expression of genes involved in lipid homeostasis and inflammation with therapeutic potential in AD $[14,23,24]$. This condition was compared to the corresponding control condition, treated only with DMSO at $0.05 \%$, given the DMSO was used for the preparation of GW3965 in the culture medium.

\subsection{Analysis of Tissue Morphology}

The tissue morphology was analyzed through a haematoxylin/eosin (H/E) staining. At the end of $48 \mathrm{~h}$ treatment, the tissues were fixed in $4 \%$ formaldehyde solution, dehydrated 
and embedded in paraffin. Sections of $6 \mu \mathrm{m}$ thick of tissue were generated using Leica microtome RM2245 and laid over microscopic slides before staining with $\mathrm{H} / \mathrm{E}$ used to visualize general tissue morphology. Slides were mounted with specific medium and examined with a Leica DM2000 photomicroscope coupled to a digital camera (Zeiss DFC420C).

\subsection{Analysis of Gene Expression Modifications}

2.6.1. Total RNA Extraction and Integrity Analysis

At the end of the treatment, total RNAs were extracted using the Qiagen RNeasy kit (Qiagen; 74106). RHE were rinsed with cold PBS and lysed in the ad hoc buffer from the kit. Extraction was performed according to the Manufacturer's instructions. The integrity of RNA was analyzed and described in Supplementary information (Figure S1). The collected RNAs were stored at $-80^{\circ} \mathrm{C}$.

\subsection{2. cDNA Synthesis}

Reverse transcription was performed with the high capacity RNA-to-cDNA kit (Applied Biosystems, Aalst, Belgium; 438706) from total RNA and the cDNAs were then stored at $-20^{\circ} \mathrm{C}$ until use in polymerase chain reactions.

\subsubsection{TaqMan Assays}

The microfluidic TaqMan qPCR arrays were designed by StratiCELL and manufactured on demand by Applied Biosystems. Data on 96 genes of interest including 3 internal controls Carbonic anhydrase (CA2), Involucrin (IVL) and Loricirin (LOR), and 1 housekeeping gene for normalization purpose, $\mathrm{B} 2 \mathrm{M}$ ( $\beta 2$-microglobuline), were gathered from the RHE samples under different conditions (Figure S2). The TaqMan arrays were processed as described by the manufacturer's instructions (Micro Fluidic Card Getting Started Guide, Applied Biosystems).

Briefly, $4 \mu \mathrm{L}$ (4 ng) of cDNA were mixed with $10 \mu \mathrm{L}$ of TaqMan Fast Advanced Master Mix (Applied Biosystems), $1 \mu \mathrm{L}$ of TaqMan Gene Expression Assay and $5 \mu \mathrm{L}$ of RNAse free water before being injected into the arrays and dispersed into the wells by centrifugation. Arrays were sealed and qPCRs were run using the Quantstudio7 Real-Time PCR System (Applied Biosystems) and its software (QuantStudio real time PCR Software v1.3., Applied Biosystems). The thermal cycles were programmed with one first denaturation step at $95^{\circ} \mathrm{C}$ for $20 \mathrm{~s}$. The amplification protocol was followed with 40 cycles $\left(1 \mathrm{~s}\right.$ at $95^{\circ} \mathrm{C}$ and $20 \mathrm{~s}$ at $\left.60^{\circ} \mathrm{C}\right)$.

All the measurements were performed from triplicates of culture $(n=3)$ and threshold cycles $\left(C_{T}\right)$ were obtained for each gene. The relative expression levels were calculated by the comparative $C_{T}\left(\Delta \Delta C_{T}\right)$ method through a combination of statistical analysis $[25,26]$. Briefly, $C_{T}$ obtained from treated condition was compared with $C_{T}$ obtained the reference condition. This average $C_{T}$ has been normalized to $C_{T}$ of B2M, the reference gene. The relative quantification $(\mathrm{RQ})$ is obtained using the formula below:

$$
\mathrm{RQ}=2^{-\left(\Delta \mathrm{C}_{\mathrm{T}} \text { treated condition }-\Delta \mathrm{C}_{\mathrm{T}} \text { reference condition }\right)}
$$

where $\Delta \mathrm{C}_{\mathrm{T}}=\mathrm{C}_{\mathrm{T}}$ [target gene $]-\mathrm{C}_{\mathrm{T}}[$ reference gene $]$ in cDNA sample.

The genes for which the $C_{T}$ values were $>36$ have been considered as non-expressed and omitted of the analysis. These include CNR1, IL6, LCE3B and SEMA3A.

In order to normalize the results, B2M was amplified from the same cDNA samples. A control without cDNA was performed in parallel as negative control of amplification to verify the absence of contaminants.

The data obtained for the condition treated with FV and UP were compared to the untreated condition stimulated by Th- 2 cytokines. The maximum $C_{T}$ cut-off value was fixed at 36 cycles. 


\subsection{Analysis of Extracellular Periostin Abundance}

The quantifications of the extracellular releases of Periostin (Thermo Scientific, EHPOSTN) were performed on the supernatants of all conditions in a specific Elisa assay.

\subsection{Bacterial Cultures, Adhesion of Bacteria, and CFU Counting}

2.8.1. Bacterial Cultures of Staphylococcus epidermis and Staphylococcus aureus

Staphylococcus aureus (ATCC 6538) and Staphylococcus epidermidis (ATCC 12228) were obtained from the American Type Culture Collection. The strains were grown in TSB (Tryptic Soy Broth) at $37^{\circ} \mathrm{C}$ under $150 \mathrm{rpm}$ and on TSA (Tryptic Soy Agar) plate.

The overnight $(\mathrm{O} / \mathrm{N})$ cultures of S. epidermidis and S. aureus were prepared in $10 \mathrm{~mL}$ of TSB medium from a fresh colony obtained by culturing S. epidermidis and S. aureus on TSA agar. The resulting cultures were then centrifuged for $10 \mathrm{~min}$ at $7000 \times g$ to harvest the cells and the pellets were re-suspended in $10 \mathrm{~mL}$ of PBS. The suspensions were then diluted 1000 fold in order to obtain an inoculum of approximately $10^{5} \mathrm{CFU} / \mathrm{mL}$.

\subsubsection{Adhesion of Bacteria and CFU Counting}

Adhesion of bacteria has been assessed by quantification of colonies on microbiological plates (Colony Forming Unit counting). After 14 days of culture at the air-liquid interface, RHE surfaces were put into contact for $30 \mathrm{~min}$ with $100 \mu \mathrm{L}$ of FV and UP at $100 \mu \mathrm{g} / \mathrm{mL}$ or $100 \mu \mathrm{L}$ of PBS for control samples. After $30 \mathrm{~min}, 100 \mu \mathrm{L}$ of the bacterial suspensions were added on the RHE surface at a concentration of $10^{5} \mathrm{CFU} / \mathrm{mL}$ for $1 \mathrm{~h}$. Control samples were treated with $100 \mu \mathrm{L}$ PBS. After the contact period, non-adherent cells were eliminated by six consecutive rinses with $300 \mu \mathrm{L}$ of sterile PBS. Finally, the adherent bacteria were collected in PBS with $0.1 \%$ Tween 80 with a swab. Both adherent and non-adherent cells were enumerated by seeding on TS agar (according to the decimal dilution method).

\section{Results}

3.1. Effects of the Test Compounds on the Morphology of RHE When Cultured under Conditions Mimicking Atopic Dermatitis

Morphology of epidermis was examined after $48 \mathrm{~h}$ of topical treatment of FV and UP by H/E staining. This was compared to RHE in the presence and absence of the GW3965 for $48 \mathrm{~h}$ (Figure 1). RHE controls (Figure 1a) presented a full differentiation of keratinocytes from basal to cornified layers resulting in the formation of the four typical layers of the epidermis, namely, basal, spinous, granular and cornified layers.

The epidermal incubation with the mix of IL-4, IL-13 and IL-25 influenced the tissue organization, indicating the tissue response to the inflamed environment (Figure $1 \mathrm{~b}, \mathrm{c}$ ). This was especially observed in the deepest layers of the RHE and more so, the basal layer, with a loss of polarized orientation of the apical-basal axis and reduced cohesion. As expected, compared to PBS (Figure 1c) DMSO (Figure 1b) did not influence any structural changes to Th2 stimulated tissue organization.

When the reference compound GW3965 was applied to the RHE, the morphological changes induced by the Th2 stimulation were considerably reduced, prohibiting the alteration of the polarized orientation of the basal layer (Figure 1d). As expected, DMSO alone did not change the morphology of the Th2-induced RHE, indicating that the GW3965 compound itself is responsible for reducing morphology change brought by cytokines (Figure 1c). The topical treatment with $100 \mu \mathrm{g} / \mathrm{mL}$ of FV and UP on Th2-induced RHE did not lead to additional morphological changes however no cytotoxicity was observed (Figure 1e,f). This supports the non-noxious impact of FV and UP on reconstructed epidermis. 


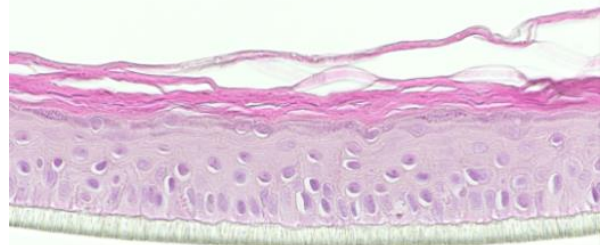

(a)

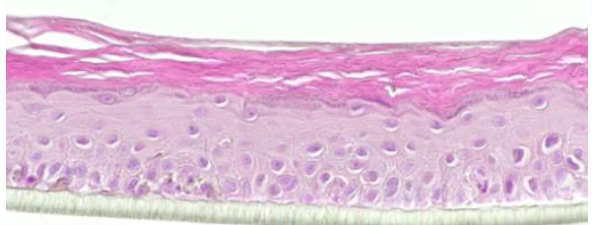

(c)

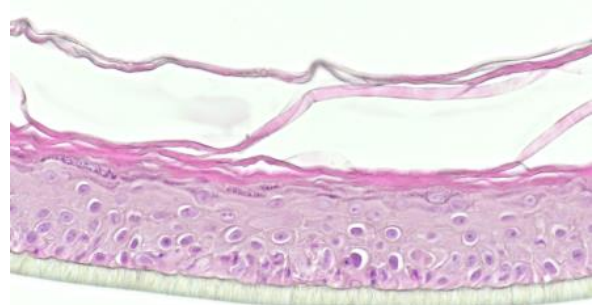

(e)

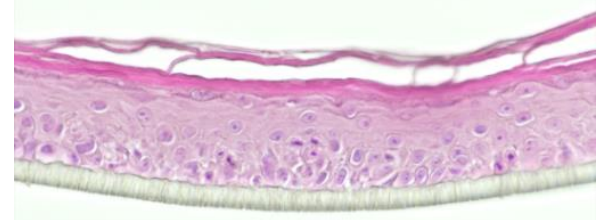

(b)

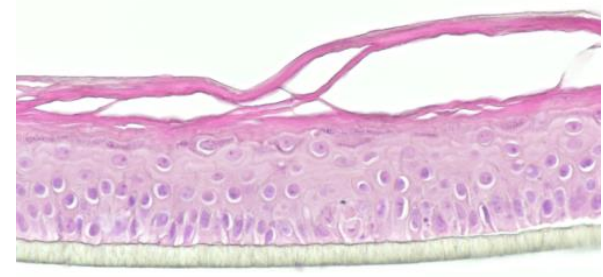

(d)

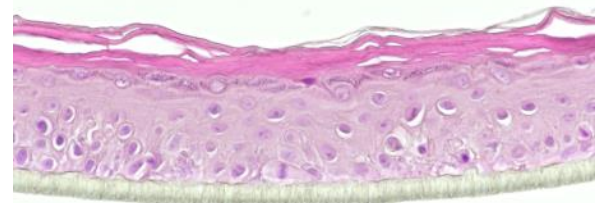

(f)

Figure 1. Histological sections of Th2-stimulated reconstructed human epidermis (RHE) after $48 \mathrm{~h}$ or topical and systemic treatments with the test compounds and reference of its solvent, respectively (H/E staining; $\mathrm{n}=1$ ). (a) control; (b) Th2 (+PBS topic); (c) Th2 + DMSO 0.05\% (d) Th2 + $10 \mu \mathrm{M}$ GW3965 in 0.05\% DMSO; (e) Th2 + $100 \mu / \mathrm{mL}$ FV; (f) Th2 + $100 \mu / \mathrm{mL}$ UP.

\subsection{Gene Expression Analysis by RT-qPCR Using TaqMan Array}

To better understand whether topical treatment of FV and UP alters any AD related gene expressions, we analyzed 93 target genes that are specifically designed to assimilate in vitro $\mathrm{AD}$ environment.

First, to validate that introduction of Th2 related cytokines (IL-4, IL-13, and IL-25) can stimulate atopic dermatitis environment, we looked at differentially expressed genes with $p$-value $<0.005$. A large number of differentially expressed genes in Th2-induced RHE were observed compared to the normal RHE environment as expected (Table 2). A global analysis of the differentially regulated genes by Th2 stimulation was carried out and volcano plot was used to highlight significant variations of gene expression (Figure 2a). 
Table 2. Differentially expressed genes that are shown significant changes. The increases are in green and decreases in red.

\begin{tabular}{cccccc}
\hline \multicolumn{5}{c}{ Th2-Induced RHE vs. RHE } \\
\hline Genes & Fold Change & $p$ Value & Genes & Fold Change & $p$ Value \\
\hline ABCA1 & 0.33 & 0.0035 & AHR & 1.67 & 0.0118 \\
CASP14 & 0.49 & 0.0177 & CA2 & 6.38 & 0.0002 \\
CCL26 & 0.43 & 0.0378 & CAPN14 & 134.80 & 0.0000 \\
CDHR1 & 0.33 & 0.0001 & CCL2/MCP1 & 3.86 & 0.0062 \\
CERS3 & 0.59 & 0.0126 & CCL27 & 2.49 & 0.0141 \\
CLDN8 & 0.24 & 0.0003 & CCL5/RANTE! & 5.02 & 0.0018 \\
CNR1 & 0.51 & 0.0346 & CH25H & 4.34 & 0.0043 \\
CXCL10 & 0.23 & 0.0061 & CTSC & 4.50 & 0.0023 \\
DGAT2 & 0.52 & 0.0081 & DUOX1 & 2.39 & 0.0279 \\
EDN1 & 0.39 & 0.007 & FZD10 & 7.23 & 0.0062 \\
FA2H & 0.23 & 0.0162 & IL13RA2 & 8.07 & 0.0012 \\
FASN & 0.66 & 0.0498 & IL2R & 14.60 & 0.001 \\
FLG & 0.53 & 0.0321 & NELL2 & 3.99 & 0.0112 \\
LCE4A & 0.58 & 0.0283 & POSTN & 8.60 & 0.0013 \\
LPIN1 & 0.54 & 0.0454 & TNC & 13.13 & 0.0034 \\
OCLN & 0.68 & 0.0477 & TNFAIP6 & 465.19 & 0.0086 \\
SEMA3A & 0.51 & 0.0336 & & & \\
SULT1E1 & 0.46 & 0.0431 & & & \\
TAC1 & 0.51 & 0.014 & & & \\
TRPV1 & 0.38 & 0.0195 & & & \\
\hline Th2 Induced RHE vs. FV Treated & Th2 Induced RHE vs. UP Treated \\
\hline Genes & Fold Change & $p$ Value & Genes & Fold Change & $p$ Value \\
\hline CD44 & 0.71 & 0.0183 & ABCA1 & 1.38 & 0.0369 \\
S100A6 & 0.51 & 0.0425 & CCL26 & 1.80 & 0.0457 \\
UGCG & 1.46 & 0.0444 & & & \\
\hline
\end{tabular}




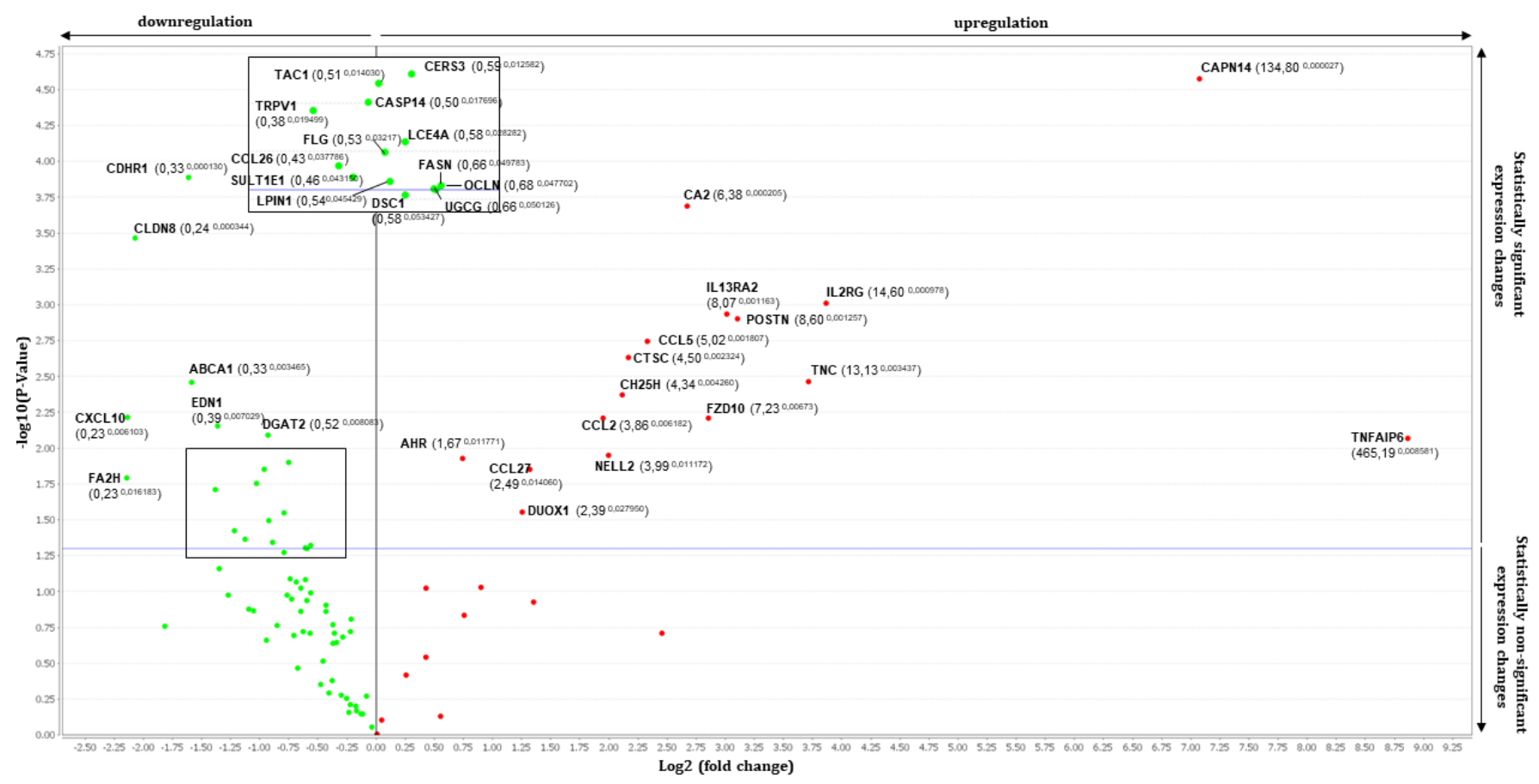

(a)

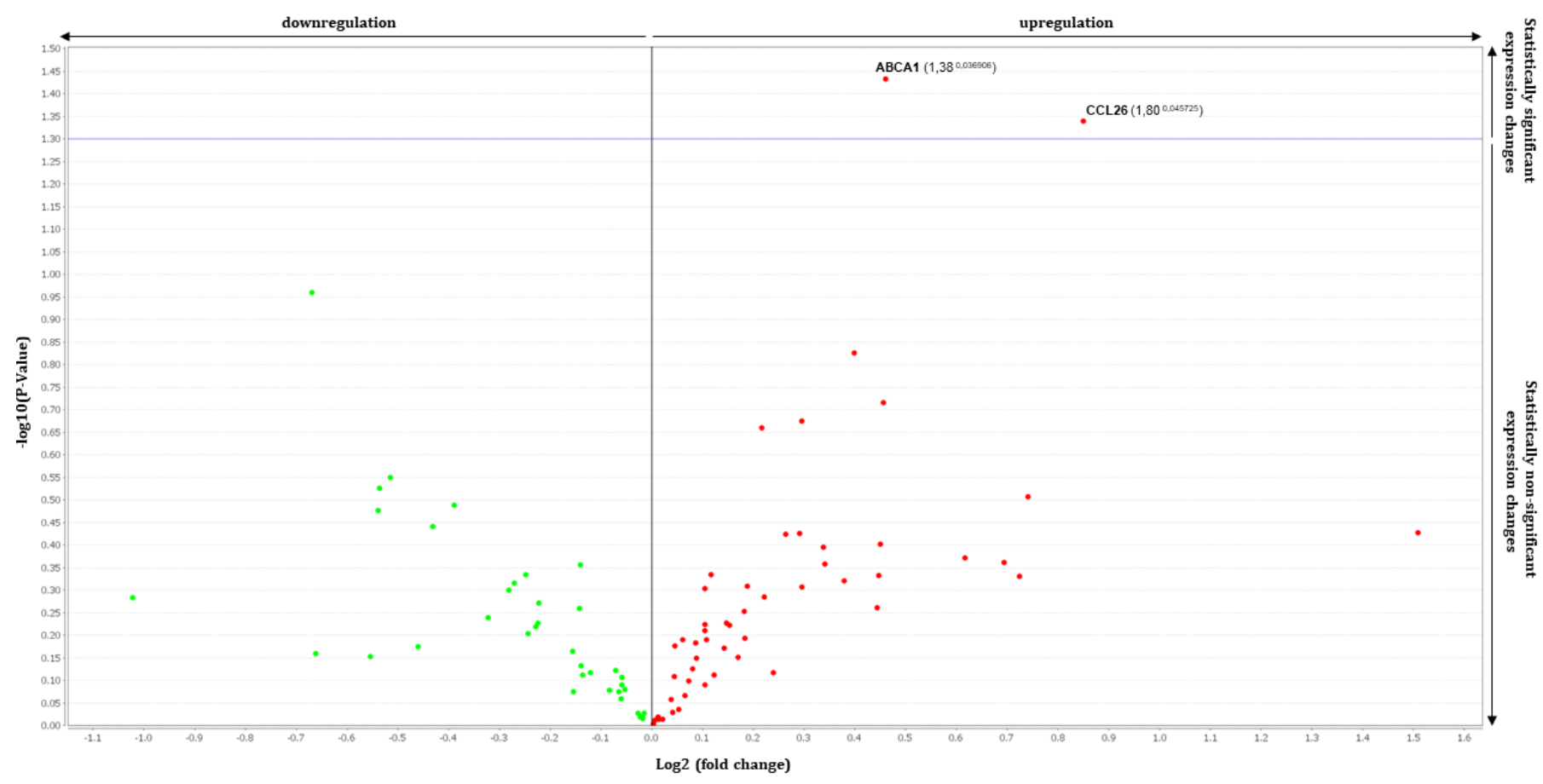

(b)

Figure 2. Cont. 


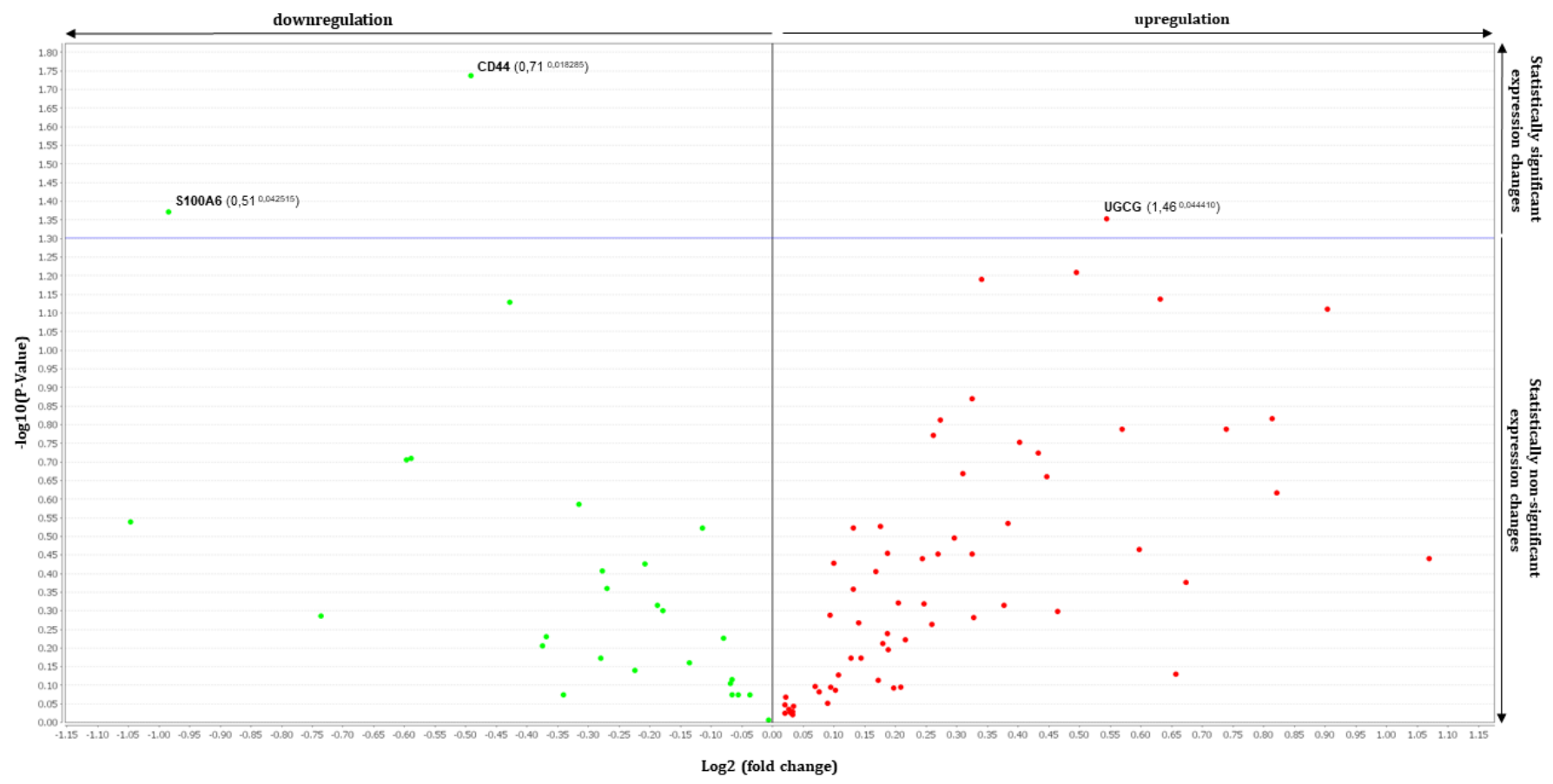

(c)

Figure 2. Volcano plots in analyzing differential gene expressions comparing between (a) control RHE and Th2 inducedRHE, (b) Th2 induced-RHE and FV treated Th2 induced-RHE and (c) Th2 induced-RHE and UP treated Th2 induced-RHE. Fold change boundary: 1 and $p$-value boundary: 0.05 .

Four genes that prompted most fold changes were TNFAIP6 (tumor necrosis factorinducible gene 6 protein), CAPN14 (Calpain-14), IL2RG (IL-2 receptor subunit gamma) and TNC (Tenascin-C). These genes are all up regulated in Th2-induced RHE and are inflammatory mediators. Moreover, NELL2 (neural epidermal growth factor-like 2) and CA2 (carbonic anhydrase 2) that are representative of atopic dermatitis and differentiates from psoriasis were also upregulated.

Down-regulated genes are OCLN, FASN, UGCG and CES3 mainly involved in barrier recovery and lipid homeostasis.

Both topical treatments of FV and UP to Th2 induced-RHE induced significant changes in the expression of a few genes compared to the stimulation alone (Table 2 and Figure $2 \mathrm{~b}, \mathrm{c}$ ). In the presence of FV, CD44 (CD44 antigen, hyaluronate receptor) and S100A6 (S100 calcium binding protein A6) were down regulated, whereas UGCG (Ceramide glucosyltransferase) was upregulated. There were many non-significant modifications and this concerns especially the regulation of genes involved in lipid homeostasis and barrier recovery (Table 3). The majority of them appear to be regulated in an opposite direction than what observed in tissue cultured in presence of Th2 cytokines alone. 
Table 3. The list for genes involved in complementary regulations about lipid homeostasis and potential regulations on barrier recovery. The increases and decreases are in green and red, respectively, and the significant $p$-values in bold.

\begin{tabular}{|c|c|c|c|c|c|c|c|}
\hline \multirow{2}{*}{ Functions } & \multirow{2}{*}{ Genes } & \multicolumn{2}{|c|}{ Th2 vs. NT } & \multicolumn{2}{|c|}{ Th 2 vs. Th $2+$ FV } & \multicolumn{2}{|c|}{ Th2 vs. Th $2+$ UP } \\
\hline & & Fold Change & $p$ Value & Fold Change & $p$ Value & Fold Change & $p$ Value \\
\hline $\begin{array}{l}\text { Triglyceride } \\
\text { synthesis }\end{array}$ & GPAT3 & 0.6214 & 0.0861 & 1.3189 & 0.1494 & 1.3213 & 0.1769 \\
\hline \multirow{2}{*}{$\begin{array}{l}\text { Fatty acid } \\
\text { synthesis }\end{array}$} & ACACA & 0.6756 & 0.1961 & 1.2663 & 0.4387 & 1.6682 & 0.1628 \\
\hline & $\mathrm{FA} 2 \mathrm{H}$ & 0.2267 & 0.0162 & 1.2280 & 0.4934 & 2.0985 & 0.3626 \\
\hline \multirow{4}{*}{$\begin{array}{l}\text { Cholesterol } \\
\text { biosynthesis } \\
\text { and transport }\end{array}$} & ABCA1 & 0.3335 & 0.0035 & 1.3755 & 0.0369 & 1.2663 & 0.0646 \\
\hline & HMGCS1 & 0.6389 & 0.1370 & 0.8291 & 0.4831 & 1.8712 & 0.0777 \\
\hline & NR1H3 & 0.7706 & 0.4183 & 1.3721 & 0.1926 & 1.1837 & 0.3636 \\
\hline & SULT1E1 & 0.4577 & 0.0431 & 0.9815 & 0.9404 & 1.7573 & 0.1530 \\
\hline \multirow{4}{*}{$\begin{array}{l}\text { Ceramide } \\
\text { synthesis }\end{array}$} & CERS3 & 0.5949 & 0.0126 & 1.0840 & 0.4628 & 1.5486 & 0.0728 \\
\hline & GBA & 0.7193 & 0.4457 & 1.3629 & 0.4651 & 1.7666 & 0.2421 \\
\hline & SMPD1 & 0.7417 & 0.1241 & 2.8455 & 0.3736 & 1.3497 & 0.1891 \\
\hline & UGCG & 0.6619 & 0.0501 & 0.9075 & 0.4411 & 1.4580 & 0.0444 \\
\hline AM defense & DEFB4A & 0.3933 & 0.0691 & 1.3601 & 0.5485 & 1.2980 & 0.4851 \\
\hline $\begin{array}{c}\text { Epidermal } \\
\text { biology }\end{array}$ & HAS3 & 5.4933 & 0.1958 & 0.4924 & 0.5206 & 0.7897 & 0.8425 \\
\hline \multirow{3}{*}{$\begin{array}{l}\text { Epidermal } \\
\text { junction }\end{array}$} & CLDN25 & 1.4695 & 0.7438 & 0.6323 & 0.6919 & 1.5768 & 0.7407 \\
\hline & OCLN & 0.6770 & 0.0477 & 1.0514 & 0.7956 & 1.2521 & 0.1352 \\
\hline & TJP1 & 0.6468 & 0.1899 & 1.6713 & 0.3112 & 1.3790 & 0.5035 \\
\hline \multirow{4}{*}{$\begin{array}{l}\text { Cornified } \\
\text { envelope } \\
\text { precursors }\end{array}$} & CASP14 & 0.4896 & 0.0177 & 0.9058 & 0.5509 & 1.3626 & 0.2183 \\
\hline & LCE2A & 0.5544 & 0.1728 & 1.6514 & 0.4677 & 1.5951 & 0.4212 \\
\hline & SPRR2A & 0.5200 & 0.2194 & 1.6174 & 0.4346 & 0.8558 & 0.7255 \\
\hline & ZNF750 & 0.8382 & 0.5563 & 0.9098 & 0.7737 & 1.5126 & 0.3437 \\
\hline
\end{tabular}

The treatment of Th2 stimulated epidermis with UP tended to reverse a greater number of Th2-related effects on gene expression than found in response to treatment with FV. Indeed, a broader panel of Th2 gene targets were inversely regulated after UP application compared to FV application (Table 3).

\subsection{Effects of the Test Compounds on Periostin Release by RHE When Cultured under Conditions Mimicking Atopic Dermatitis}

To investigate whether the FV and UP treatment could modulate the protein expression of periostin, a well-known maker of $\mathrm{AD}$ [15-18], the analysis was performed by a specific immunoassay (ELISA) targeting periostin. The changes of periostin production are shown in Figure 3a,b. 


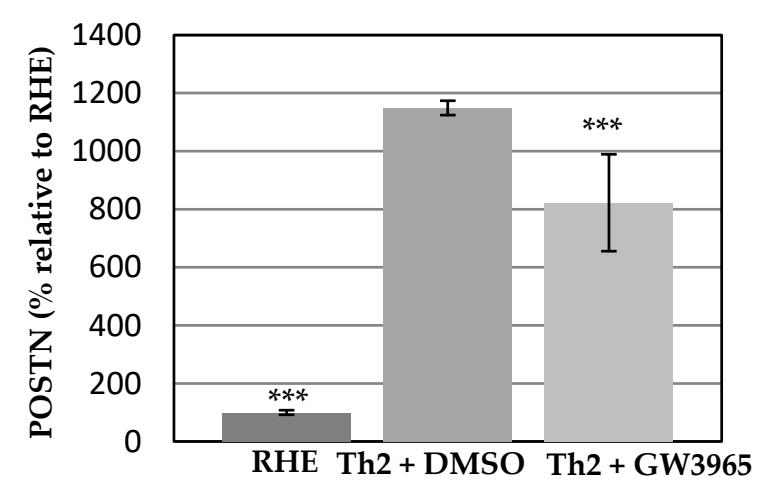

(a)

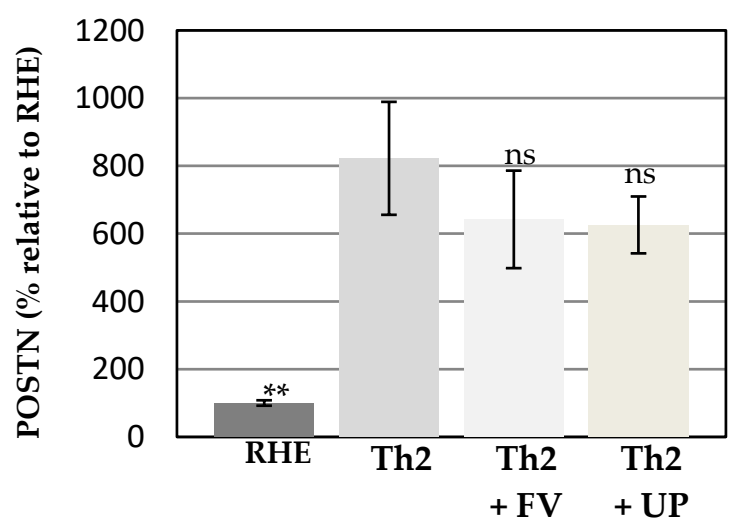

(b)

Figure 3. Changes in the periostin (POSTN) abundance in (a) Th2-induced RHE in $0.05 \%$ DMSO and in the presence of GW3965 and (b) in the presence of FV and UP. Data are given in percentage relative to the untreated condition. (*** $p<$ $0.001,{ }^{* *} 0.001<p<0.01$ and $\left.\mathrm{ns} p>0.05\right)$.

The Th2 stimulation (+DMSO) induced a strong and significant production of periostin as compared to unstimulated condition (Figure 3a). As expected, the presence of GW3965 allowed to significantly decrease this induction, favoring a return towards a basal level of protein expression [14].

The Th2 challenge combined with topical application of PBS triggered an important and significant release of periostin. It is interesting to note that the induction level of periostin protein expression was found similar to those of its gene expression, supporting the relevance to study this marker in the present model. In a similar way, the addition of FV or UP stimulated a reduced production of periostin shown in Figure 3b. Although not significant, this downward tendency supports a protective effect of FV and UP treatments on the regulation of periostin.

\subsection{Adhesion of Bacteria}

Staphylococcus aureus colonizes the skin of majority of atopic dermatitis patients and it could lead to increase disease severity. To test whether fucoidan could prevent or minimize bacteria adhesion, we evaluated the impact of FV and UP at $100 \mu \mathrm{g} / \mathrm{mL}$ on the adhesion of Staphylococcus epidermidis, Staphylococcus aureus and Cutibacterium acnes on RHE. Adhesion of bacteria has been assessed by quantification of colonies on microbiological plates after collection of adherent and non-adherent cells from the RHE tissues, as explained in the methods.

There was no significant effect neither with FV or UP on the adhesion of the commensal S. epidermidis (Figure 4a). However, a significant reduction of S. aureus adhesion was observed upon prior topical application of FV and UP on the stratum corneum of RHE (Figure $4 \mathrm{~b}$ ). Furthermore, topical application of FV and UP reduces the adhesion of the $C$. acnes (Figure 4c). 


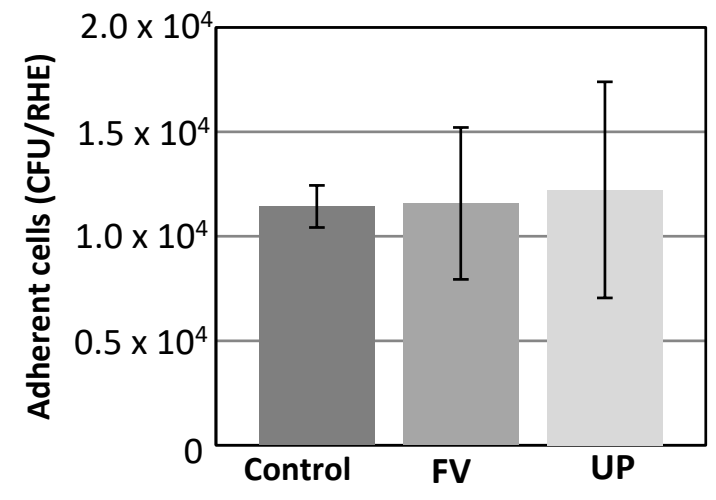

(a)

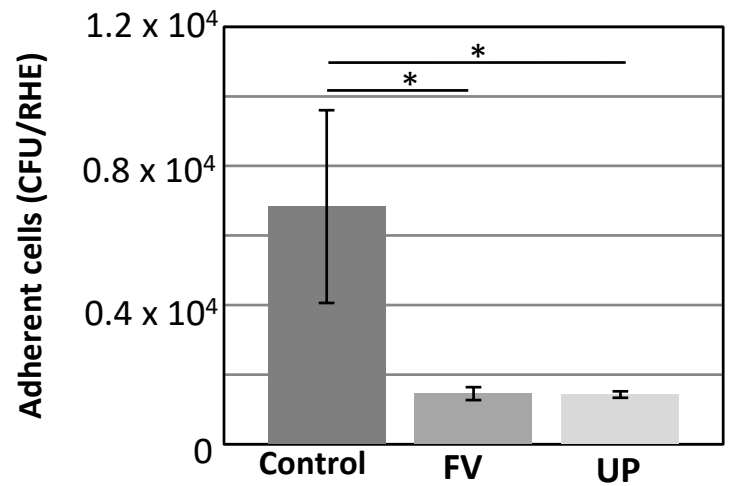

(b)

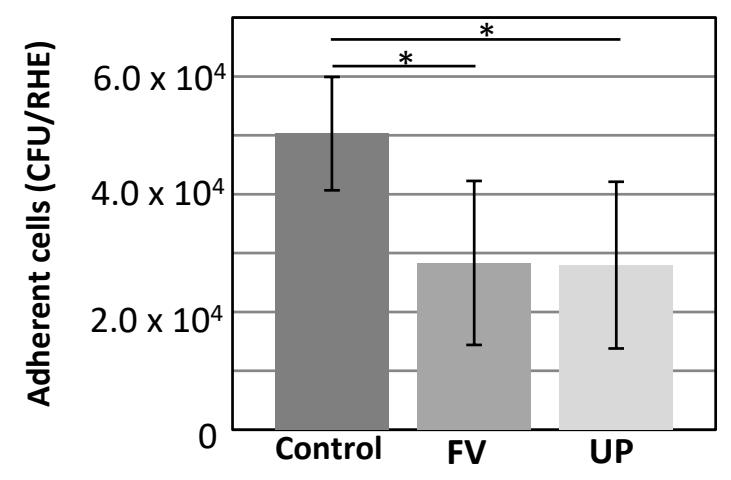

(c)

Figure 4. Concentrations of adherent (a) S. epidermidis, (b) S. aureus and (c) C. acnes after topical treatment with FV and UP. The concentrations are expressed in CFU/RHE. The graph represents the means obtained on three independent cultures with three counts for each of them, as well as the standard deviation. The values of $0.001<p<0.05$ are considered as significant $\left({ }^{*}\right)$. Student's test compared to control.

\section{Discussion}

Sensitive skin with atopic tendency and atopic eczema are common skin problems/diseases associated with altered epidermal barrier and, for the most severe cases, chronic inflammation. Atopic dermatitis has a strong Th2 component associated with IL-4 and IL-13 over-production by Th2-polarized lymphocytes in the acute phase of the disease.

The RHE model mimicking an inflammatory context through Th2 cytokines stimulation and used in this study was fully characterized by the demonstration of the dysregulation of many genes involved in skin barrier, lipid metabolism and transport, axon guidance and inflammation. These data are in correlation with other published studies on closely related in vitro models $[14,22,27,28]$.

Both treatments of Th2-induced RHE with FV and UP stimulated significant changes in expression of a few genes compared to the Th2 induction alone. Insoluble lipids require specific transport mechanisms or carriers such as ABCA1 to move them through the cytoplasm [29]. Keratinocytes require abundant cholesterol for cutaneous permeability barrier function, hence the regulation of cholesterol homeostasis is of great importance. $\mathrm{ABCA} 1$ is a ubiquitous membrane transporter responsible for cholesterol efflux and plays pivotal role in regulating cellular cholesterol levels. A significant decrease of the ABCA1 expression following Th2 stimulation was restored and increased its expression by 1.38 fold by FV. Therefore, FV considerably improve or stabilize the cholesterol homeostasis, through the up-regulation of ABCA1, in tissues whose barrier function is impaired in context of Th2 inflammation. 
Interestingly, FV also induced the significant gene regulations of CCL26, a chemokine involved in the recruitment of inflammatory cells. The increased expression of the Th2down-regulated chemokine may support the ability of FV to reverse the Th2 effect, but also promote the recruitment of cells involved in wound healing process [30,31].

The differential expression of CD44, the receptor for hyaluronic acid, was also reversed in the presence of UP. Increased expression of the hyaluronic synthase 3 (HAS3) by Th2 stimulation was also decreased in response to FV application. These co-regulated genes may indicate the ability of fucoidan to act on the metabolism of hyaluronic acid and related pathways, and more so, to counteract spongiosis, a hallmark of eczema [32]. In spongiosis, keratinocytes lose cohesiveness with a decreased expression of cadherins, as a water influx into the epidermal intercellular spaces occurs together with an accumulation of hyaluronate (HA). This phenomenon is associated with an increased expression of CD44, the major receptor of HA and HAS3. All these components are known to be up-regulated in lesional AD skin as a consequence to Th2 inflammation [32-35].

S100A6 encodes for a calcium binding protein of the S100 family and is implied in the regulations of the differentiation process of keratinocyte [36] and was down-regulated by UP. The overexpression of this gene of the S100 family in keratinocyte is associated with an undifferentiated status of the cell. Therefore, the great down-regulation of S100A6 by the test compound could demonstrate a promoted differentiation of keratinocyte.

UGCG participates in the glycosylation of ceramides. One of remarkable and epidermisspecific ceramide species is acylceramides and they are essential for skin barrier formation. Decreases in acylceramide levels as well as alteration in ceramide composition and chain-length are associated with cutaneous disorders such as ichthyosis and psoriasis, and represented a hallmark of AD [37,38]. Upregulation of UGCG by UP could, therefore, have a positive effect on ceramides metabolism in the skin, by a return to normal level and on the restoration of the resulting barrier function in the event of an inflammatory challenge.

A large number of subtle modifications were also observed (Table 3). The majority of affected genes are involved in lipid homeostasis and barrier recovery and are regulated in an opposite way compared to Th2-induced RHE. Although not significant, all these subtle but concomitant regulations might demonstrate a bundle of evidence which acts in complementarity to generate epidermal benefits against AD-related detrimental effects. Therefore, fucoidan could act in favor of a reinforced and more resistant epidermal barrier, alleviating the damages associated with sensitive skin and AD.

Most importantly fucoidan significantly inhibited adhesion of $S$. aureus which is typically abundant in skins of AD patients and aggravate the condition [39]. However, interestingly fucoidan did not affect the adhesion of S. epidermidis, usually innocuous commensal skin bacteria. It is unclear how fucoidan differentiates between S. aureus and S. epidermidis. As a relatively hydrophobic bacteria, S. epidermis was found to adhere to stainless steel more effectively than to reconstituted skin. However, the opposite was true for S. aureus which is known to have a basic and hydrophilic surface [40]. We speculate that negatively charged fucoidan binds to $S$. aureus thereby preventing it to adhere to the RHE in this study.

Interestingly, antimicrobial activity against E. coli and S. aureus of fucoidan has been observed before [41] and showed a great potential as an antiadhesive biomaterial coating agent that stops infection of $S$. aureus for urinary catheter applications [42].

Acne is a common skin disease which affects $9.4 \%$ of the global population [43] and over-colonization of Cutibacterium acnes is one of the main triggers for acne. Interestingly, recent studies indicated that the balance of $C$. acnes and S. epidermidis population on skin is very important as S. epidermidis can limit C. acnes over-colonization [44]. Considerable inhibition of adhesion of $C$. acnes and maintenance of $S$. epidermidis population may potentiate fucoidan as a beneficial therapeutic agent in acne treatment. 


\section{Conclusions}

Topical application of fucoidan from Fucus versiculosus and Undaria pinnatifida leads to non-cytotoxic impact on the 3D reconstructed human epidermis. Together with beneficial gene regulation, subtle inhibition of periostin release and remarkable inhibition of $S$. aureus adhesion, fucoidan offers a promising therapeutic potential against skin inflammatory disease such as atopic dermatitis and related damages.

Supplementary Materials: The following are available online at https:/ /www.mdpi.com/2296-352 9/8/2/12/s1, Figure S1: Analysis of the integrity of extracted RNA through their electrophoresis profiles, Figure S2: Modifications of the gene expression of 3 targets from reconstructed epidermis after $48 \mathrm{~h}$ of treatment with Th2-like cytokines in presence or absence of GW3965.

Author Contributions: Conceptualization, J.H.F., R.H., M.S.; methodology, R.H., M.S., A.C.; formal analysis, C.L., M.B., A.C.; investigation, C.L., M.B.; writing—original draft preparation, A.Y.P., J.H.F.; writing-review and editing, A.Y.P., J.H.F., R.H.; visualization, C.L., M.B., A.C.; All authors have read and agreed to the published version of the manuscript.

Funding: This research was funded by Marinova Pty Ltd., located in Cambridge, Tasmania, Australia. Institutional Review Board Statement: Not applicable.

Informed Consent Statement: Not applicable.

Conflicts of Interest: Ah Young Park and Janet Helen Fitton are employees of Marinova Pty Ltd. Maureen Bourtembourg, Aline Chrétien, Roland Hubaux, Céline Lancelot and Michel Salmon are employees of StratiCELL.

\section{References}

1. Lee, B.W.; Detzel, P.R. Treatment of Childhood Atopic Dermatitis and Economic Burden of Illness in Asia Pacific Countries. Ann. Nutr. Metab. 2015, 66 (Suppl. 1), 18-24. [CrossRef]

2. Fitton, H.J.; Stringer, D.S.; Park, A.Y.; Karpiniec, S.N. Therapies from Fucoidan: New Developments. Mar. Drugs 2019, 17, 571. [CrossRef] [PubMed]

3. Fitton, J.H.; Stringer, D.N.; Karpiniec, S.S. Therapies from Fucoidan: An Update. Mar. Drugs 2015, 13, 5920-5946. [CrossRef]

4. Lee, K.Y.; Jeong, M.R.; Choi, S.M.; Na, S.S.; Cha, J.D. Synergistic effect of fucoidan with antibiotics against oral pathogenic bacteria. Arch. Oral Biol. 2013, 58, 482-492. [CrossRef] [PubMed]

5. Oka, S.; Okabe, M.; Tsubura, S.; Mikami, M.; Imai, A. Properties of fucoidans beneficial to oral healthcare. Odontology 2020, 108, 34-42. [CrossRef] [PubMed]

6. Baba, M.; Snoeck, R.; Pauwels, R.; de Clercq, E. Sulfated polysaccharides are potent and selective inhibitors of various enveloped viruses, including herpes simplex virus, cytomegalovirus, vesicular stomatitis virus, and human immunodeficiency virus. Antimicrob. Agents Chemother. 1988, 32, 1742-1745. [CrossRef]

7. Ikegami-Kuzuhara, A.; Yoshinaka, T.; Ohmoto, H.; Inoue, Y.; Saito, T. Therapeutic potential of a novel synthetic selectin blocker, OJ-R9188, in allergic dermatitis. Br. J. Pharm. 2001, 134, 1498-1504. [CrossRef] [PubMed]

8. Iwamoto, K.; Hiragun, T.; Takahagi, S.; Yanase, Y.; Morioke, S.; Mihara, S.; Kameyoshi, Y.; Hide, M. Fucoidan suppresses IgE production in peripheral blood mononuclear cells from patients with atopic dermatitis. Arch Derm. Res. 2010, 303, 425-431. [CrossRef]

9. Yang, J.H. Topical Application of Fucoidan Improves Atopic Dermatitis Symptoms in NC/Nga Mice. Phytother. Res. 2012, 26, 1898-1903. [CrossRef] [PubMed]

10. Tian, T.; Chang, H.; He, K.; Ni, Y.; Li, C.; Hou, M.; Chen, L.; Xu, Z.; Chen, B.; Ji, M. Fucoidan from seaweed Fucus vesiculosus inhibits 2,4-dinitrochlorobenzene-induced atopic dermatitis. Int. Immunopharmacol. 2019, 75, 105823. [CrossRef]

11. Frankart, A.; Malaisse, J.; De Vuyst, E.; Minner, F.; de Rouvroit, C.L.; Poumay, Y. Epidermal morphogenesis during progressive in vitro 3D reconstruction at the air-liquid interface. Exp. Derm. 2012, 21, 871-875. [CrossRef] [PubMed]

12. Pastore, S.; Mascia, F.; Gulinelli, S.; Forchap, S.; Dattilo, C.; Adinolfi, E.; Girolomoni, G.; Di Virgilio, F.; Ferrari, D. Stimulation of purinergic receptors modulates chemokine expression in human keratinocytes. J. Invest. Derm. 2007, 127, 660-667. [CrossRef]

13. Bieber, T. Atopic dermatitis. Ann. Derm. 2010, 22, 125-137. [CrossRef]

14. Hubaux, R.; Bastin, C.; Salmon, M. On the relevance of an in vitro reconstructed human epidermis model for drug screening in atopic dermatitis. Exp. Derm. 2018, 27, 1403-1407. [CrossRef] [PubMed]

15. Mishra, S.K.; Wheeler, J.J.; Pitake, S.; Ding, H.; Jiang, C.; Fukuyama, T.; Paps, J.S.; Ralph, P.; Coyne, J.; Parkington, M.; et al. Periostin Activation of Integrin Receptors on Sensory Neurons Induces Allergic Itch. Cell Rep. 2020, 31, 107472. [CrossRef] [PubMed] 
16. Sung, M.; Lee, K.S.; Ha, E.G.; Lee, S.J.; Kim, M.A.; Lee, S.W.; Jee, H.M.; Sheen, Y.H.; Jung, Y.H.; Han, M.Y. An association of periostin levels with the severity and chronicity of atopic dermatitis in children. Pediatr. Allergy Immunol. 2017, 28, 543-550. [CrossRef] [PubMed]

17. Kou, K.; Okawa, T.; Yamaguchi, Y.; Ono, J.; Inoue, Y.; Kohno, M.; Matsukura, S.; Kambara, T.; Ohta, S.; Izuhara, K.; et al. Periostin levels correlate with disease severity and chronicity in patients with atopic dermatitis. Br. J. Dermatol. 2014, 171, 283-291. [CrossRef]

18. Shiraishi, H.; Masuoka, M.; Ohta, S.; Suzuki, S.; Arima, K.; Taniguchi, K.; Aoki, S.; Toda, S.; Yoshimoto, T.; Inagaki, N.; et al. Periostin contributes to the pathogenesis of atopic dermatitis by inducing TSLP production from keratinocytes. Allergol. Int. 2012, 61, 563-572. [CrossRef]

19. Maeda, D.; Kubo, T.; Kiya, K.; Kawai, K.; Matsuzaki, S.; Kobayashi, D.; Fujiwara, T.; Katayama, T.; Hosokawa, K. Periostin is induced by IL-4/IL-13 in dermal fibroblasts and promotes RhoA/ROCK pathway-mediated TGF-beta1 secretion in abnormal scar formation. J. Plast. Surg. Hand. Surg. 2019, 53, 288-294. [CrossRef] [PubMed]

20. De Vuyst, E.; Giltaire, S.; Lambert de Rouvroit, C.; Malaisse, J.; Mound, A.; Bourtembourg, M.; Poumay, Y.; Nikkels, A.F.; Chretien, A.; Salmon, M. Methyl-beta-cyclodextrin concurs with interleukin (IL)-4, IL-13 and IL-25 to induce alterations reminiscent of atopic dermatitis in reconstructed human epidermis. Exp. Derm. 2018, 27, 435-437. [CrossRef] [PubMed]

21. De Vuyst, E.; Mound, A.; Lambert de Rouvroit, C.; Poumay, Y. Modelling atopic dermatitis during the morphogenetic process involved in reconstruction of a human epidermis. Curr. Res. Transl. Med. 2016, 64, 179-183. [CrossRef] [PubMed]

22. De Vuyst, E.; Salmon, M.; Evrard, C.; Lambert de Rouvroit, C.; Poumay, Y. Atopic Dermatitis Studies through In Vitro Models. Front. Med. 2017, 4, 119. [CrossRef]

23. Fowler, A.J.; Sheu, M.Y.; Schmuth, M.; Kao, J.; Fluhr, J.W.; Rhein, L.; Collins, J.L.; Willson, T.M.; Mangelsdorf, D.J.; Elias, P.M.; et al. Liver $X$ receptor activators display anti-inflammatory activity in irritant and allergic contact dermatitis models: Liver-X-receptor-specific inhibition of inflammation and primary cytokine production. J. Invest. Derm. 2003, 120, $246-255$. [CrossRef]

24. Schmuth, M.; Jiang, Y.J.; Dubrac, S.; Elias, P.M.; Feingold, K.R. Thematic review series: Skin lipids. Peroxisome proliferatoractivated receptors and liver $X$ receptors in epidermal biology. J. Lipid Res. 2008, 49, 499-509. [CrossRef]

25. Livak, K.J.; Schmittgen, T.D. Analysis of relative gene expression data using real-time quantitative PCR and the 2(-Delta Delta C(T)) Method. Methods 2001, 25, 402-408. [CrossRef]

26. Pfaffl, M.W. A new mathematical model for relative quantification in real-time RT-PCR. Nucleic Acids Res. 2001, 29, e45. [CrossRef]

27. Goleva, E.; Berdyshev, E.; Leung, D.Y. Epithelial barrier repair and prevention of allergy. J. Clin. Investig. 2019, 129, 1463-1474. [CrossRef]

28. Berardesca, E.; Farage, M.; Maibach, H. Sensitive skin: An overview. Int. J. Cosmet. Sci. 2013, 35, 2-8. [CrossRef]

29. Tarling, E.J.; de Aguiar Vallim, T.Q.; Edwards, P.A. Role of ABC transporters in lipid transport and human disease. Trends Endocrinol. Metab. 2013, 24, 342-350. [CrossRef] [PubMed]

30. Gaspar, K.; Kukova, G.; Bunemann, E.; Buhren, B.A.; Sonkoly, E.; Szollosi, A.G.; Muller, A.; Savinko, T.; Lauerma, A.I.; Alenius, H.; et al. The chemokine receptor CCR3 participates in tissue remodeling during atopic skin inflammation. J. Derm. Sci. 2013, 71, 12-21. [CrossRef] [PubMed]

31. Rees, P.A.; Greaves, N.S.; Baguneid, M.; Bayat, A. Chemokines in Wound Healing and as Potential Therapeutic Targets for Reducing Cutaneous Scarring. Adv. Wound Care 2015, 4, 687-703. [CrossRef] [PubMed]

32. Barnes, L.; Carraux, P.; Saurat, J.H.; Kaya, G. Increased expression of CD44 and hyaluronate synthase 3 is associated with accumulation of hyaluronate in spongiotic epidermis. J. Invest. Derm. 2012, 132 (Pt 1), 736-738. [CrossRef]

33. Man, M.; Elias, P.M.; Man, W.; Wu, Y.; Bourguignon, L.Y.; Feingold, K.R.; Man, M.Q. The role of CD44 in cutaneous inflammation. Exp. Derm. 2009, 18, 962-968. [CrossRef]

34. Malaisse, J.; Bourguignon, V.; De Vuyst, E.; Lambert de Rouvroit, C.; Nikkels, A.F.; Flamion, B.; Poumay, Y. Hyaluronan metabolism in human keratinocytes and atopic dermatitis skin is driven by a balance of hyaluronan synthases 1 and 3 . J. Investig. Derm. 2014, 134, 2174-2182. [CrossRef]

35. Lugovic-Mihic, L.; Novak-Bilic, G.; Vucic, M.; Japundzic, I.; Bukvic, I. CD44 expression in human skin: High expression in irritant and allergic contact dermatitis and moderate expression in psoriasis lesions in comparison with healthy controls. Contact Dermat. 2020, 82, 297-306. [CrossRef]

36. Graczyk, A.; Lesniak, W. S100A6 expression in keratinocytes and its impact on epidermal differentiation. Int. J. Biochem Cell Biol 2014, 57, 135-141. [CrossRef] [PubMed]

37. Lee, A.Y. Molecular Mechanism of Epidermal Barrier Dysfunction as Primary Abnormalities. Int. J. Mol. Sci. 2020, 21 , 1194. [CrossRef]

38. Ohno, Y. Elucidation of the Synthetic Mechanism of Acylceramide, an Essential Lipid for Skin Barrier Function. Yakugaku Zasshi 2017, 137, 1201-1208. [CrossRef]

39. Nakatsuji, T.; Chen, T.H.; Narala, S.; Chun, K.A.; Two, A.M.; Yun, T.; Shafiq, F.; Kotol, P.F.; Bouslimani, A.; Melnik, A.V.; et al. Antimicrobials from human skin commensal bacteria protect against Staphylococcus aureus and are deficient in atopic dermatitis. Sci. Transl Med. 2017, 9. [CrossRef] [PubMed] 
40. Lerebour, G.; Cupferman, S.; Bellon-Fontaine, M.N. Adhesion of Staphylococcus aureus and Staphylococcus epidermidis to the Episkin reconstructed epidermis model and to an inert 304 stainless steel substrate. J. Appl. Microbiol. 2004, 97, 7-16. [CrossRef] [PubMed]

41. Jesumani, V.; Du, H.; Pei, P.; Aslam, M.; Huang, N. Comparative study on skin protection activity of polyphenol-rich extract and polysaccharide-rich extract from Sargassum vachellianum. PLoS ONE 2020, 15, e0227308. [CrossRef]

42. Mohan, K.; Ravichandran, S.; Muralisankar, T.; Uthayakumar, V.; Chandirasekar, R.; Seedevi, P.; Abirami, R.G.; Rajan, D.K. Application of marine-derived polysaccharides as immunostimulants in aquaculture: A review of current knowledge and further perspectives. Fish. Shellfish Immunol. 2019, 86, 1177-1193. [CrossRef] [PubMed]

43. Tan, J.K.; Bhate, K. A global perspective on the epidemiology of acne. Br. J. Dermatol. 2015, 172 (Suppl. 1), 3-12. [CrossRef] [PubMed]

44. Claudel, J.P.; Auffret, N.; Leccia, M.T.; Poli, F.; Corvec, S.; Dreno, B. Staphylococcus epidermidis: A Potential New Player in the Physiopathology of Acne? Dermatology 2019, 235, 287-294. [CrossRef] [PubMed] 